\title{
IMPACT OF COVID-19 PANDEMIC ON PROJECT PORTFOLIO MANAGEMENT-A CASE STUDY ON CONSTRUCTION INDUSTRY IN SOUTHERN INDIA
}

\author{
Ajay Krishnan, Ajithkumar S, Manishankar G, Upendra K, Kabilan A, Dr P Muralidhar* \\ National Institute of Construction management And Research (NICMAR), Hyderabad, India
}

\author{
Date received: 07/04/2021 Date accepted: 04/09/2021 \\ *Corresponding author's email: pmuralidhar17@gmail.com \\ DOI: $10.33736 /$ jcest.3981.2021
}

\begin{abstract}
In India, Project Portfolio Management (PPM) is in practice as a tool for prioritizing and managing real estate projects in construction organizations. But due to insufficient funding, improper judgment of experts during the crisis situation, the selection of optimal project portfolio prototype can be viewed as a risk based decision making process involving various risk factors. The objective of this study is to analyze the importance of project portfolio management and the risks associated with it in the construction industry taking into account the impact of novel corona virus COVID-19. This research identifies the adoption of more consistent project governance, risk management techniques and way more careful project portfolio management as the core area of study. A conceptual framework for Project Portfolio Management is also designed after analyzing various parameters of Project Portfolio Management of construction industry with the help of Bayesian framework. The key motive for undertaking this part of examination on real estate sector of Indian construction industry in southern part of India to reduce the impacts and increase the return on investment from the projects by mitigating the effect of risk factors associated in the projects. Project Portfolio Management tools and techniques are very useful for managing multiple construction projects.
\end{abstract}

Copyright (C) 2021 UNIMAS Publisher. This is an open access article distributed under the Creative Commons Attribution-Non Commercial-Share Alike 4.0 International License which permits unrestricted use, distribution, and reproduction in any medium, provided the original work is properly cited.

\section{Keywords: Project Portfolio management (PPM), Bayesian network, COVID-19, Pandemic, Risk}

\subsection{INTRODUCTION}

In the Country like India, managing a project portfolio at a given time is not a difficult task for a construction organization. The problem arises when organizations handles multiple projects simultaneously during pandemic times or crisis times. Most of today's construction organizations are executing several projects concurrently which creates lot of pressure in terms of risk, cost and time management of all the projects. The process of managing different project portfolios is known as project portfolio management (PPM). To understand PPM firstly we have to understand about project management [1]. Project management is nothing but management of an organized set of activities targeted towards acommon goal, using specialized management tools and techniques. Project portfolio management involves following stages like in selection stage, the new projects are selected on the basis of data collected about the project and financial analysis. Whether it is feasible to finish the project within the estimated budget or if any financial risks may arise during the project. In planning and scheduling stage, all activities are planned and scheduled in such way to reach objective in the best way so that other projects in the company should not be disturbed. In execution stage, resources should be allocated by considering priority and maximum utilization of resource should be made. In monitoring and controlling stage, the project needs to be controlled by finding alternatives to mitigate them. This will explain how project management and project portfolio management vary with a correlation that when these two managements are put together that would ultimately carrying the right projects in a right way to attain success is nothing but managing the portfolios in the projects[2].

PPM is very useful management technique for organizations, it accounts for the data collection of every project and that is to be organized into respective identical portfolios so that project portfolios can easily be studied and monitored for progress and reviewed whether the project had measurable profit and quality of work in execution [3]. The main purpose of the project portfolio management is to line up projects, plan and execute them with available resources, monitor them and keep all intricate parties informed about their status. Project portfolio management follows a top-down approach. The purpose of project portfolio management is to achieve the objectives of the organization by aligning its resources, capabilities, strategic objectives in a single line. This 


\section{Journal of Civil Engineering, Science and Technology}

Volume 12, Issue 2, September 2021

ensures that important, less risky projects are implemented first and for that the necessary resources will be made available and then the remaining resources are made ready to use it for the next consecutive projects [4].It helps in resource planning as well as creating value to business.

Companies working on a massive number of projects, it is easy to make strategic decisions. When a company does not use project portfolio management, they often route into the problem of implementing too many unimportant projects in an inappropriate time. This practice also makes the projects get terminated due to low quality or simply because they are not feasible. All these points add on to the importance of project portfolio management in construction projects [5]. This particular niche of PPM in construction projects in India during economic recession period like COVID 19 is our area of study in this project. Hereby, a conceptual framework is proposed to review the project portfolio management process by taking into account the knowledge of experts in the real estate sector. This will be done by using a Bayesian network modeling and with the support of project portfolio management software tools. This research paper is systematized in a way that the second part contains the flowchart developed for the analysis purpose, the third part contains the research part related to Bayesian networking methodology, and then the fourth part contains data analysis [6].

\subsection{FLOWCHART}

Different methods have been applied to analyze project portfolio management in different scenarios. For time being we have adopted the COVID -19 situations and analyzed project portfolio management in such a never seen before crisis situations for the construction industry with the help of Bayesian networks. A software called Bayesia lab 19 was used to analyze the various impacts which will greatly affect the real estate sector in this corona pandemic situation [7]. These impacts are risk impact, cost impact and project impact. The road map which is followed for our project is shown below to elaborate each flowchart component.

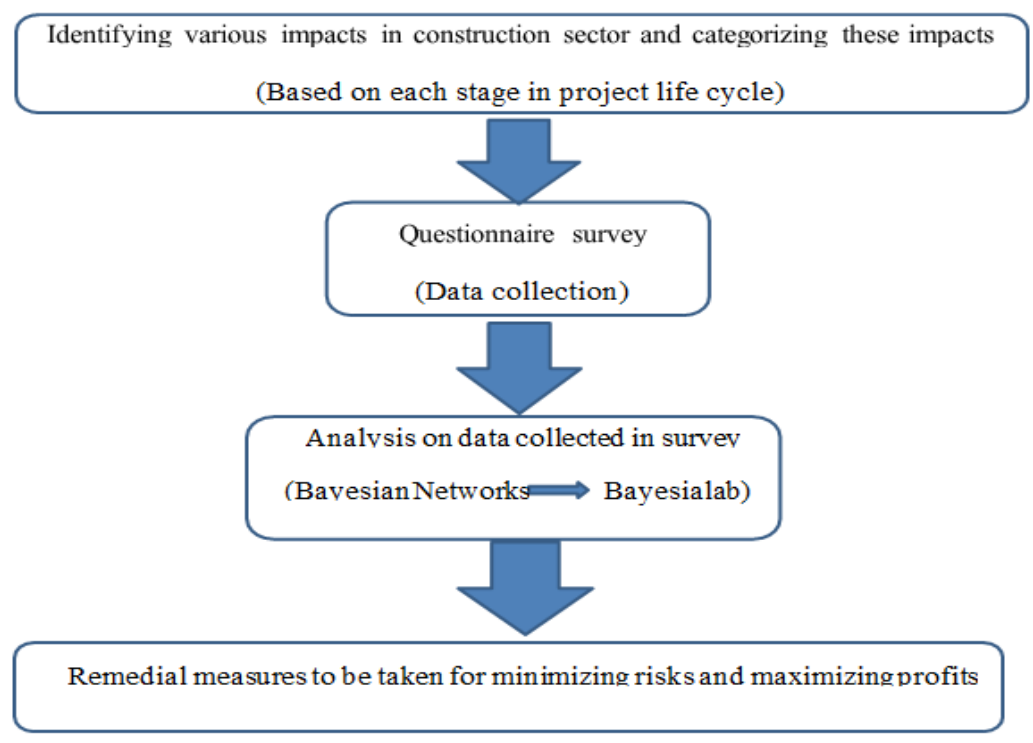

Figure 1 Flow chart

The last part of the flow chart explains that if the impact is high then some remedial measures are to implemented to bring to the normal situation.

\subsection{METHODOLOGY}

\subsection{Methodology Description}

There is a lot of uncertainty and risks is common in major projects and they must be effectively managed to produce successful projects [8]. Some careful management techniques may be implemented for major projects to reduce uncertainty and risk. Assessment of uncertainty is a major cause for the disappointing project outcomes. Our study is to understand the effect of COVID-19 in construction industry and to propose a significant method for portfolio 


\section{Journal of Civil Engineering, Science and Technology}

Volume 12, Issue 2, September 2021

management of projects to mitigate the impact of COVID-19. This project presents a Bayesian network (BN) modelling to calculate the effect of COVID-19 in the portfolio management of construction industry in terms of three major parameters namely project impact, cost impact and risk impact of construction at changing circumstances like construction before COVID-19 and construction during COVID-19 [9]. The BN framework uses hybrid and dynamic approaches. Bayesian network comprising of continuous variables over studying the particular parameters. The BN framework estimates the impact of COVID-19 in construction based on multiple causal factors including the effects of individual risk factors, budget factors, and project impact factors [10]. This framework can serve as the basis for various project portfolio management assessments and is illustrated using a real estate development portfolio project. We have made a survey for seeking expert knowledge over this effect of COVID-19 in construction industry. This surveyed information caters the need of acquiring the expert knowledge over three parameters namely project impact, cost impact and risk impact on construction industry by COVID- 19 . From this survey responses, we have proposed a Bayesian network modelling using Bayesialab software for a real estate development portfolio project in two different scenarios namely before and during COVID-19 circumstances. Our framework aims to model multiple parameters affecting the process of construction before undertaking a project and during the construction to pre-estimate the impacts of pandemic situation like COVID-19 in the construction industry [11].

This Bayesian Network is a powerful tool for creating probabilistic inference on complex areas with huge number of variables. It was coined by Judea Pearl in 1985 to emphasize the analysis of subjective nature of the input information available. $\mathrm{BN}$ is a graphical model based on probabilistic approach that consists of a graphical structure and parameters of conditional probability distributions corresponding to the structure. The structure of a BN is composed of nodes, represents variables, and arcs represents the relations between the variables. The parameters of a BN represent the nature and strength of the relations represented by the arcs. The graphical structure of a BN is suitable for modelling causal relations. Therefore, BNs offers features like integrating expert knowledge and data in developing the model. This is beneficial in the situations where the data availability is limited and unlimited expert knowledge is available. The dynamic discretization algorithm in $\mathrm{BN}$ is helpful to solve hybrid $\mathrm{BN}$ models involving arbitrary continuous distributions accurately, efficiently and conveniently [12].

\subsection{Questionnaire Survey}

A questionnaire survey method is used for gathering statistical information related to the attributes, attitudes of a available population using the structured set of questions. Since we were in need of a quantitative data for our analysis, we framed the questionnaire with closed ended modes. we have considered several major impacts in construction industry in two cases namely pre- COVID -19 days and during COVID -19 times, respondents can respond on a scale of 1 to 5. The results of this survey would be analysed and it will be given as input parameters for Bayesialab software is used to make detailed analysis to achieve objectives [13].

\subsubsection{Framing of Questionnaire}

Project portfolio management in construction industry during pandemic there was a need to compare pre and during pandemic situations. Here pre pandemic situation is till the month of March, 2020. For the purpose of the study, we assumed a real estate company in the name of XYZ which will have a portfolio of its own in a pessimistic situation i.e., the company exists in a bad market condition. We also selected three impacts which will affect the portfolio of this company and will be common to both pre COVID-19 and during COVID -19 situation. The impacts are risk impact, project impact and cost impact. Out of these three impacts, the risk and cost impacts will be on the portfolio of the company and the other impact i.e., project impact is the impact caused by the projects of the company. Therefore, the questions in the survey were categorized under these three impacts project impact, risk impact and cost variance impact respectively [14].

\subsubsection{Project Impact}

A real estate project upon its completion will have the following three impacts in the location where it is constructed. They are livelihood impact, social impact and environmental impacts. The livelihood impact deals with the effect of Corona pandemic on the livelihood of the professionals and migrant workers who are the major resources in the construction industry. It also deals about the living standard of people who are the buyers in the real estate sector. The social impact tells about the impact created by the real estate projects in the places in which they are 


\section{Journal of Civil Engineering, Science and Technology}

Volume 12, Issue 2, September 2021

constructed. It will discuss about the development of that particular place because of the project which is getting executed there, the buying capacity of the customers, the socio economic growth of that place. The environmental impact is the impact which is resulting from a facility's activities or services on the surrounding environment. Three questions were included in the survey for these three impacts respectively which will showcase what impact a real estate project will have on a particular locality.

\subsubsection{Risk Impact}

This is the most common and prevailing impact in the construction industry. There will be many risks in the industry related to time, quality, safety, labor, procurement,finance, equipment/machinery etc. From the above mentioned risks, we excluded financial risk since that will be deal incostimpact and we framed five questions which will be based on delay in project completion, Men and machinery shortage and unskilled labor, Resource mobility, Procurement of material and Safety precautions

\subsubsection{Cost Variance Impact}

Unlike infrastructure projects, the company has to bear the cost escalations in real estate projects. This provides the need to analyze cost impacts on real estate projects. Cost impacts were prepared as questions under various stages of construction i.e. pre- construction stage during construction stage and post construction stage. Pre-construction stage deals with cost variations arising due to changes in the plan and design. During construction stage deals with difficulties while construction is going on like quality, strength, performance. Post construction stage will deal with the profits of the company i.e. whether the company has yielded the projected return on investment or not.

\subsection{DATA ANALYSIS}

Analysis of data is nothing but of inspection, collection, transferring and modeling of data for ascertaining useful information, for decision making aspects. In the current research paper the data obtained from the questionnaire was analyzed, results are tabulated and used as inputs for the Bayesialab software.

\subsection{Data Collection}

For collection of data, the sample to which the questionnaire has to be circulated should be identified and the mode in which questionnaire should be sent has to be decided.

\subsubsection{Sampling Design}

\subsubsection{Population}

The population constitutes of professionals working in the construction industry.

\subsubsection{Sampling Technique}

The prepared questionnaire was sent to the professionals and responses were collected based ontheir individual experience and their roles in their respective organizations. The questionnaire consisting of 12 questions was sent to 140 professionals as a Google form via a link. A total of 107 responses were recorded.

\subsection{Reliability Test}

Reliability test is performed to the extent to which test scores are not affected by chance factors by the luck of the draw. Reliability test revels us how consistently the test scores are portraying. Reliability is concerned with whether the results of a study are repeatable. A construct composite reliability co-efficient (Cronbach's alpha) of 0.7 or above, for all the constructs, was considered to $\mathrm{c}$ a r r y o u t this study. The acceptable reliability coefficient is 0.6 and above (Cronbach's Alpha) was used to test the reliability of the research instrument. In our study, the Cronbach's alpha value is 0.72 which is above the acceptable limit. This shows that the data collected for our study is reliable to conduct the analysis [15]. 


\section{Journal of Civil Engineering, Science and Technology}

Volume 12, Issue 2, September 2021

Table 1 Reliability Statistics Results

\begin{tabular}{|c|c|c|}
\hline Cronbach's Alphavalue & Cronbach's Alpha Basedon Standardized Items & Number ofItems \\
\hline 0.716 & 0.705 & 22 \\
\hline
\end{tabular}

\subsection{Project Impact}

The project impact estimate component models the targets for different categories of impact expected from the project. Although impact is often transformed to monetary value, categories of impact are likely to differ in different portfolios. We have focused on three main impacts of any project portfolio namely livelihood impact, social impact and environmental impact for constructionbefore and during COVID-19 in real estate development portfolio project. The analysis of impact of the particular project or portfolio of project is very much essential to develop the goodwill of a construction firm by means of improving the livelihood of the people by way of new employments, improved standard of living, socio-economic development of the nation and implementation of some green construction techniques to preserve the surrounding environmental condition and to have considerable savings in usage of virgin resources for construction. This analysis on project portfolio impact will greatly influence the decision of a construction developer to undertake a project or portfolio of projects under COVID 19 situation. The expert knowledge on the project portfolio impact is acquired from the responses of survey and these responses are based on the scale values of five ordinal states ranging from 'Very Low' to 'Very High' with the corresponding scale from ' 1 to 5 '. Based on the expert's responses the discrepancies are estimated and observed project portfolio impact will have effect on goodwill of project portfolio of the company.

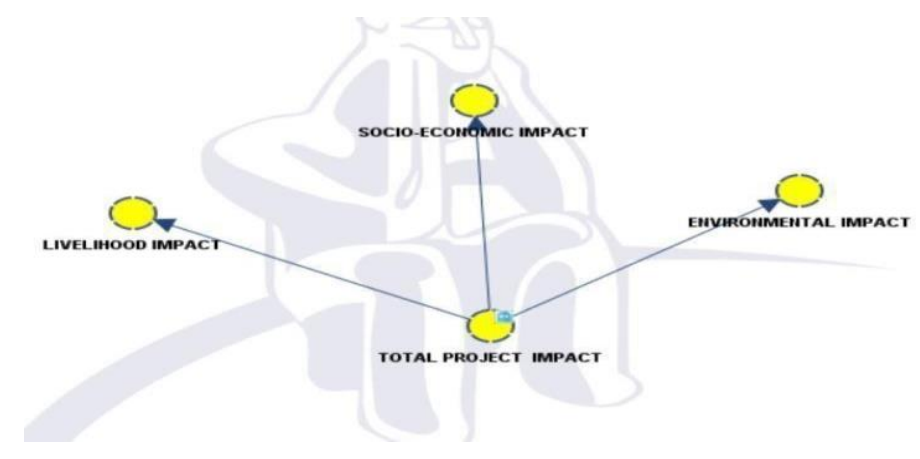

Figure 2 Bayesian Networks for Impact by project portfolio management

\subsection{Risk Impact}

BNs are used to develop the models related to uncertainty and risk attributes that are common to all. BNs are used specially in complex probability distributions with abundant random variables. The data related to various projects is always differs with respect to time and cost consuming pattern in case of short and long run projects. In such cases expert knowledge is utilized for effective portfolio management with a source of evidence. This implies that portfolio management applies expert knowledge and analysis of data for attaining better results. The risk estimation model compares both the estimated risk and observed risk to give better insight. In this study, we have considered five major risks involved in the construction industry that has massive impacts on the progress of the construction in a real estate development portfolio project. The risk parameters that we have considered here will be same in both scenarios i.e. before and during COVID-19 with the only difference in their intensity of occurrence practically. The expert knowledge over the risk occurrence is acquired from the responses of survey and these responses are based on the scale values of five ordinal states ranging from 'Very Low' to 'Very High' with the corresponding scale from ' 1 to 5 '. If no risks have been considered,then the risk estimate will be assigned to the value 'Very Low' and if the risks have been considered, then the risk estimate will be assigned to the value accordingly from 'Low to Very High'. The discrepancies in the estimated and observed risk will have effect on cost of the project. As we aimed to relate the risks more practical, we have framed five major risk factors that are moreuncertain and effective in nature. 


\section{Journal of Civil Engineering, Science and Technology}

Volume 12, Issue 2, September 2021

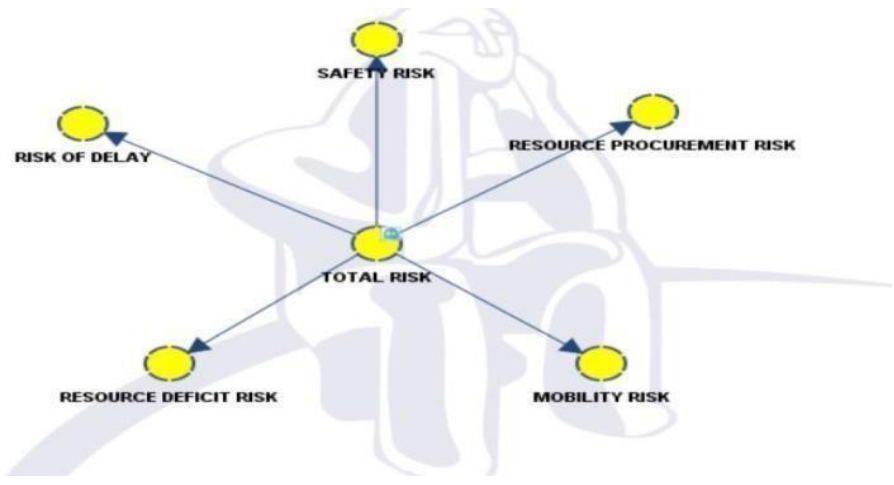

Figure 3 Bayesian Networks for Project Portfolio Risk Impact

\subsection{Cost Variance Impact}

The cost variance impact $(\mathrm{BN})$ comprises of the variations in different kinds of cost impacts that arises throughout the construction period of the project portfolio of a company. This parameter is subcategorized into three nodes based on different stages of construction namely (a) pre construction cost variance impact where the initial investments other planning and designing cost for a project portfolio is incurred,(b) cost variance impact during construction, where the upkeep cost impact and other cost impact relating to the practical conditions in terms of productivity and other challenging circumstances of the construction, (c) post-construction cost variance impact, where the original reality on fulfilling the scope of the project portfolio is accomplished or if there is any deviations of end outcome of the project portfolio with respect to the expected or pre-designed outcome. As we are focusing on the cost variance impact rather than the direct cost, it will illustrate the effect of COVID 19 in much more effective and provide us the absolute key factors involving in the final budget determination of the project portfolio. The expert knowledge on the cost variance impact is acquired from the responses of survey and these responses are based on the scale Values of five ordinal states ranging from 'Very Low' to 'Very High' with the corresponding scale from ' 1 to 5'. Based on the intensity of the cost impact on all the three stages of construction, the expertise responses are assigned from the scale of ' 1 to 5'(Very Low to Very High). The discrepancies in the estimated and observed cost impact will have positive and negative effect on cost of the project portfolio [16].

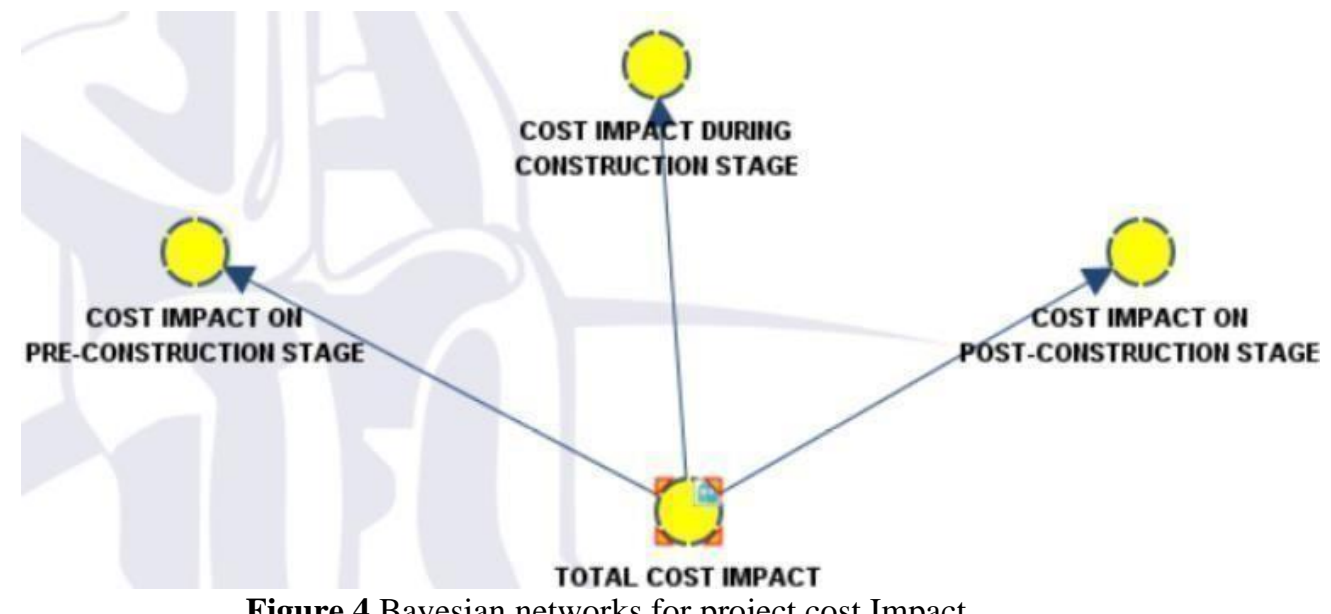

Figure 4 Bayesian networks for project cost Impact

\subsection{RESULTS \& DISCUSSIONS}

The three impacts namely, project impact, risk impact and cost variance impact were analyzed in pre Covid 19 and during Covid 19 situations with the help of Bayesialab software. Comparison of the impacts in both pre Covid 19 and during Covid 19 situations was studied and it is given in the following figures. These observations will clearly show a picture how the Covid 19 pandemic has affected the real estate sector of the construction industry in southern part of India 


\section{Journal of Civil Engineering, Science and Technology}

Volume 12, Issue 2, September 2021

\subsection{Comparison of Project Impact}

This comparative analysis on impact by project portfolio shows mixed results, the lively hood impact of workers are there and environmental impact is marginal where as social economic impact is almost nil as per the fig 5. During COVID19 is approximately 53\% of high and very high ordinate impact which is as same as the impact by project portfolio before COVID19. The impact by project portfolio during COVID19 is $14.64 \%$ which is less than $21.87 \%$ of impact by project portfolio before COVID19. This decline in the impact by project portfolio during COVID19 is due to slow or delayed progress of the project and its adverse effect on livelihoodof the people. So we can say that project portfolio management has mixed results before and during Covid 19.

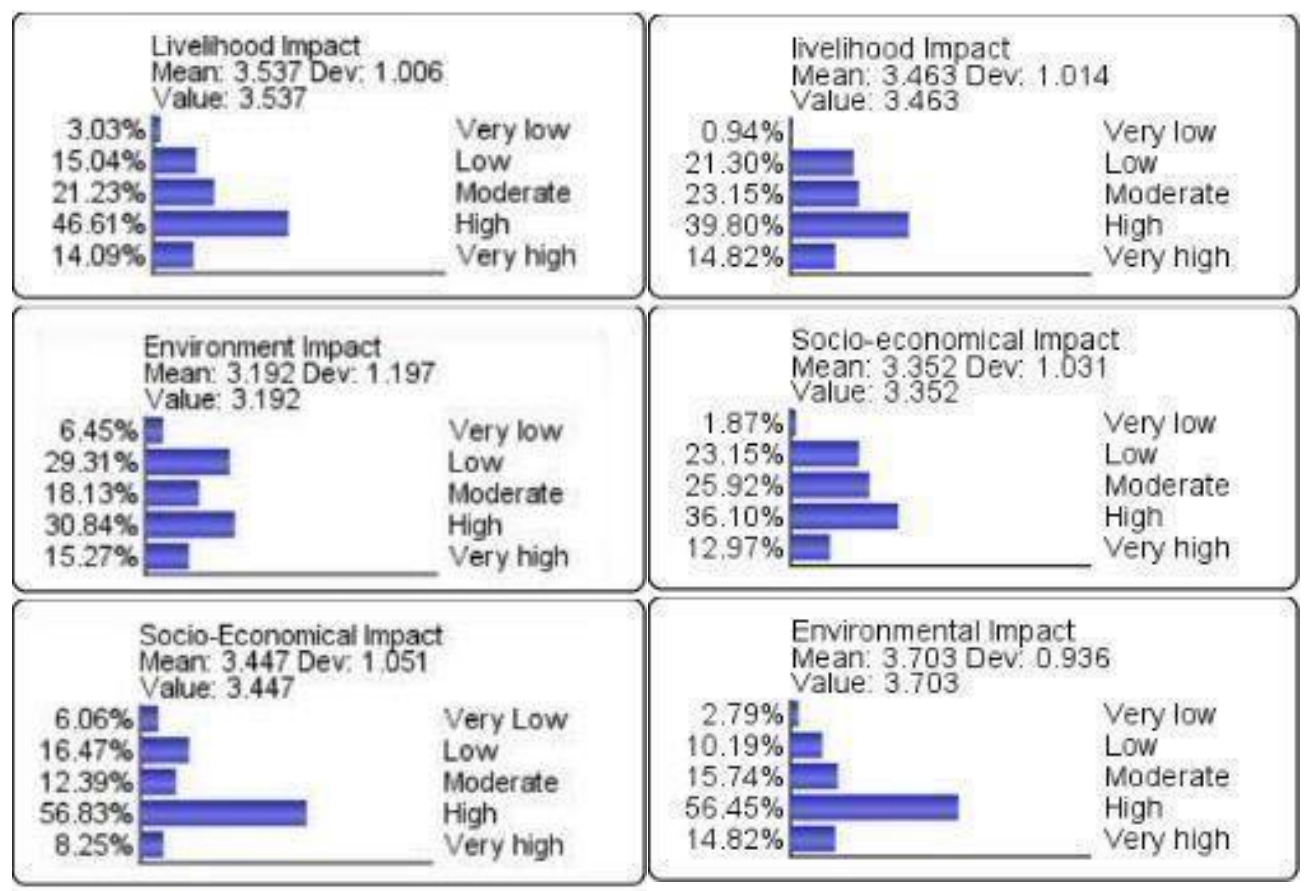

Figure 5 Results of Impacts by Project Portfolio before and during COVID19

Hence inorder to understand the impact by project portfolio illustratively, we observed the percentage of impact by project portfolio in both situations with respect to very high ordinate of impact. The impact by project portfolio during COVID19 is $12.66 \%$ whichis less than $16.17 \%$ of impact by project portfolio before COVID19. This decline in the impact by project portfolio during COVID19 is due to adverse effect on livelihoodof the people associated to the project portfolio of the XYZ Company.

\section{Before COVID19}

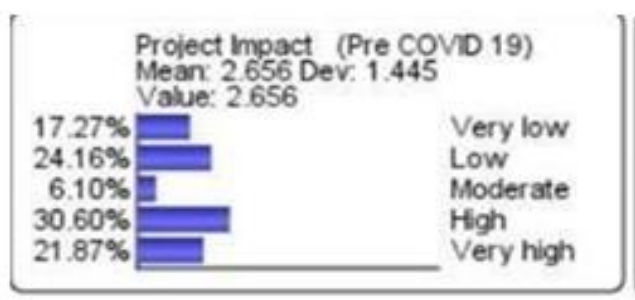

\section{During COVID19}

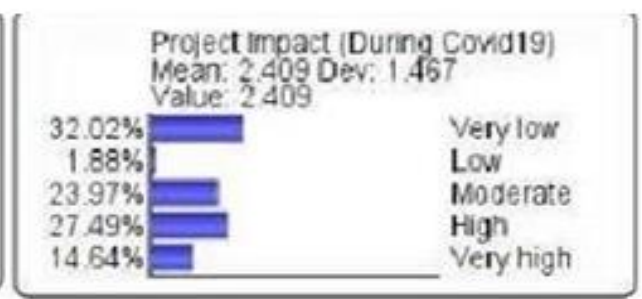

Figure 6 Comparison of project impact before COVID-19 and During COVID-19

\subsection{Comparison of Risk Impact}

As we can observe from the comparative analysis of the project portfolio risk portrayed in the fig 8 portfolio risk of the XYZ company during COVID19 will be more to that of the project portfolio risk before COVID19 (approximately $61 \%$ of high and very high ordinate risk) to that of the project portfolio risk before COVID19 


\section{Journal of Civil Engineering, Science and Technology}

Volume 12, Issue 2, September 2021

(approximately 32\% of high and very high ordinate risk). The difference of about $29 \%$ of high and very high ordinate of project risks during COVID19 should be addressed efficiently to mitigate the adverse risk impact. The reason is due to the non-availability of labor project is getting delayed, causes high level of risk. Then the harmony of work is completely disturbed and risk impact level is more.
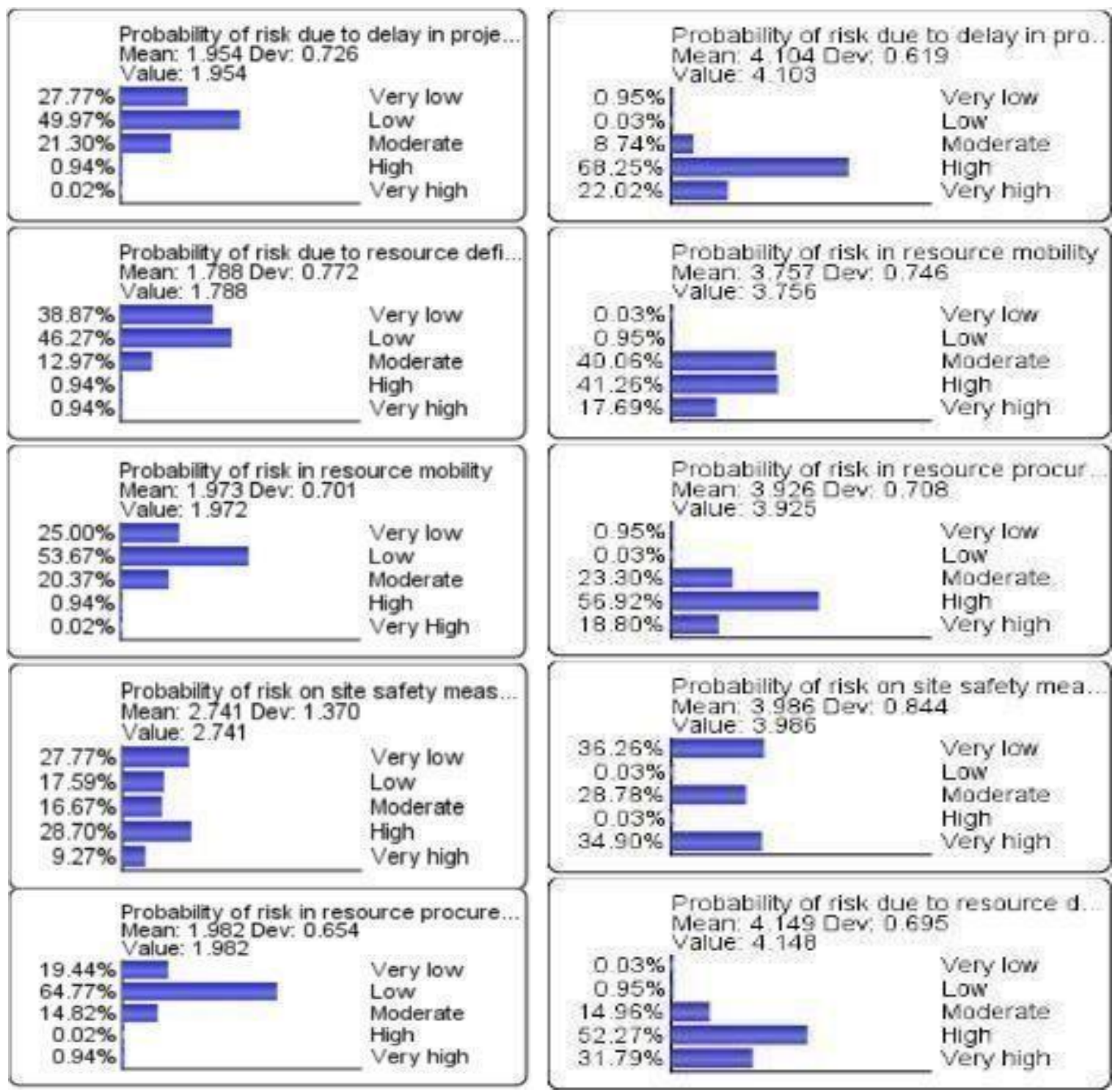

Figure 7 Results of Risk Impacts before COVID19 during COVID 19

Before COVID19

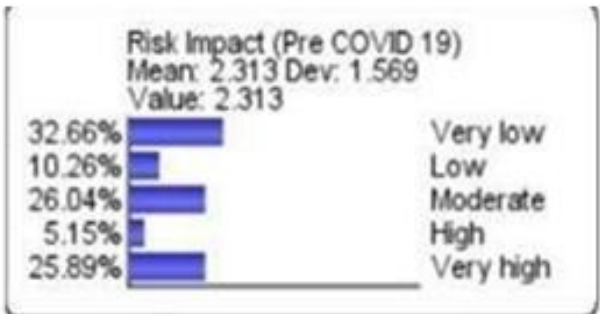

\section{During COVID19}

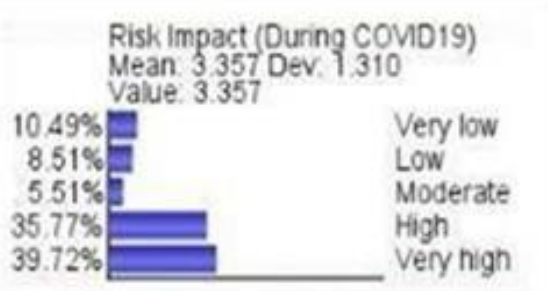

Figure 8 Comparison of Risk Impact before and During COVID 19 


\section{Journal of Civil Engineering, Science and Technology}

Volume 12, Issue 2, September 2021

\subsection{Comparison of Cost Variance Impact}

From the comparative analysis of the cost variance impact on project portfolio, we can clearly note that the cost variance impact on project portfolio before COVID 19 has approximately 53 percent of high and very high ordinate impact which is as same as the impact by project portfolio before COVID19 has approximately $29 \%$ of cost variance impact in high and very high ordinates which is less than $39 \%$ of cost variance impact in high and very high ordinates in the project portfolio during COVID19. This hike of about $10 \%$ of cost variance impact is high it was due to escalation of material prices and manpower cost due to Covid 19.
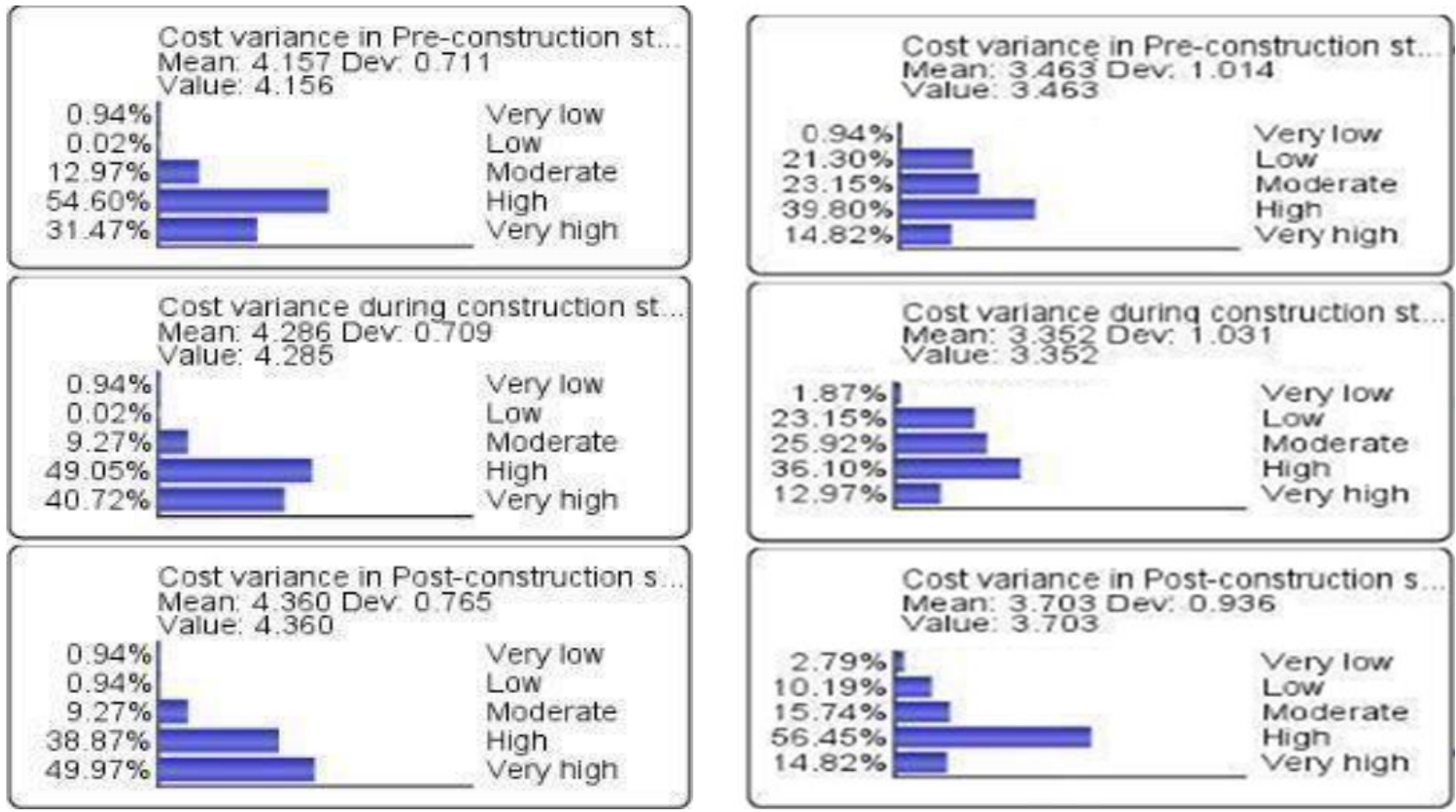

Figure 9 Results of Cost Impacts before COVID19

\section{Before COVID19}

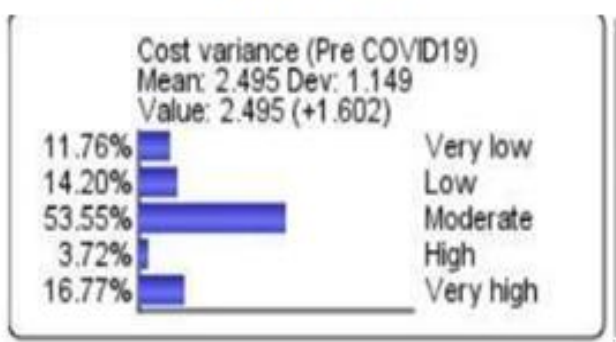

During COVID19

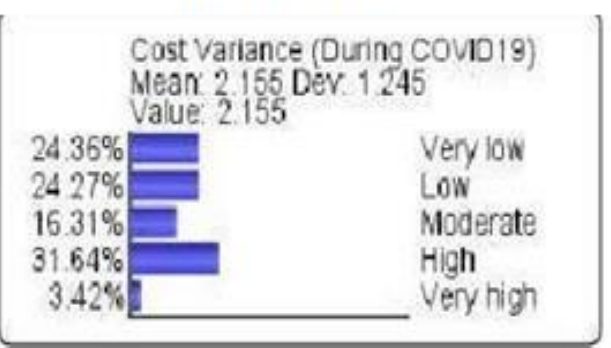

Figure 10 Comparison of cost variance impact before and During COVID 19

\subsection{CONCLUSION}

It is evident from the results table that the parameter in the project impact like labor migration is having a maximum impact, but other impacts like environmental concerns are less, lively hood effect is there in workers community. Socio economic concerns are also there in workers community and became difficult to migrate to other jobs.

In case of a risk Impact, the risk level is very high for the projects in terms of non-availability of materials, nonavailability of labor as well as machinery. Due to these problems the uncertainty became more in projects. The problem faced is during unlocking period mobilizing the quality of resources became big challenge for many companies and quality of work is significantly effected and the project has undergone severe risk level as portrayed 


\section{Journal of Civil Engineering, Science and Technology}

Volume 12, Issue 2, September 2021

in table 2.

The cost impact point of view many construction projects faced the higher materials cost due to low production of materials, transportation cost of materials. Due to this the cost of the project was escalated and there is a delay in the execution time of the project also. The project impact is observed some down fall during Covid 19 time.

Table 2 Bayesian network analysis output

\begin{tabular}{|c|c|r|r|c|}
\hline & & Pre COVID19 & During COVID19 & \\
\hline S.no & Impact & Probability \% & Probability \% & Net Impact by COVID19 \\
\hline 1 & Risk Impact & 31.04 & 75.49 & $44.45 \%$ (Hike) \\
\hline 2 & Cost Variance Impact & 20.49 & 35.06 & $14.57 \%$ (Hike) \\
\hline 3 & Project Impact & 52.47 & 42.13 & $10.34 \%$ (Downfall) \\
\hline
\end{tabular}

All the above results are obtained based on the answers obtained from the different respondents who are working on different construction companies in southern India. The Bayesian network modeling was very useful in calculating the certainty and uncertainty level analysis. We can understand from the table the construction projects have under gone high level of risk during Covid 19 time followed by cost variance impact. But the Project impact in terms of environment and socio economic point of view only positive impact can be seen in the results table 2. This is because of the non-functioning of so much machinery as well restricted working conditions. It is evident that there is a huge necessity of implementing precautionary or remedial measures to overcome this pandemic situation. These types of analysis is needed nowadays to mitigate the upcoming risks in the projects and will pave way to complete the construction projects during challenging times.

\section{References}

[1] Horváth, V. (2019). Project management competence-definitions, models, standards and practical Implications. Vezetéstudomány-Budapest http://dx.doi.org/10.14267/VEZTUD.2019.11.01

Management Review, 50(11),

2-17.

[2] Walker, A. (2015). Project management in construction. John Wiley \& Sons.

[3] Al-Kilidar, H., \& Davis, S. (2011). Towards Project Portfolio Management for Sustainable Outcomes in the Construction Industry. PMOZ 8th Annual Project. Available from: https://opus.lib.uts.edu.au/handle/10453/17446

[4] Baptestone, R., \&Rabechini, R. (2018). Influence of portfolio management in decision making. Journal of Industrial Engineering and Management, 11(3), 406-428. https://doi.org/10.3926/jiem.2464

[5] Gamil, Y., \&Alhagar, A. (2020). The Impact of Pandemic Crisis on the Survival of Construction Industry: A Case of COVID-19. Mediterranean Journal of Social Sciences,11(4). https://doi.org/10.36941/mjss-2020-0047.

[6] Linwang, S., Wang, Y., Cai, J., \& Long, Y. (2016). A Three Dimensional ProjectPortfolio Management Framework for Companies. The Open Civil Engineering Journal, 10(1), $179-188$. https://doi.org/10.2174/18741495016100101.

[7] Krishnan, S. R., Selvan, K. ., \& Kumar, S. S. (2017). Impact of Demonetisation on Construction Industry. International Journal of Economics and Management Studies, 4(1), $24-27$. https://doi.org/10.14445/23939125/ijems-v4i1p104.

[8] Voss, M. (2012). Impact of customer integration on project portfolio management and its success-Developing a conceptual framework. International Journal of Project Management, 30(5), 567-581. http://doi.org/10.1016/j.ijproman.2012.

[ 9] Romessis, C., \& Mathioudakis, K. (2006). Bayesian network approach for gas path fault diagnosis

[10] Yet, Barbaros, Anthony Constantinou, Norman Fenton, Martin Neil, Eike Luedeling, and Keith Shepherd (2016). A Bayesian network framework for project cost, benefit and risk analysis with an agricultural development case study, Expert Systems with Applications.

[11] Goldszmidt, M. (2010). Bayesian network classifiers. Wiley Encyclopedia of Operations Research and Management Science.

[12] Rabelo, C. C., Feres, M., Gonçalves, C., Figueiredo, L. C., Faveri, M., Tu, Y. K., \& Chambrone, L. (2015). Systemic antibiotics in the treatment of aggressive periodontitis. A systematic review and a Bayesian Network metaanalysis. Journal of Clinical Periodontology, 42(7), 647-657. https://doi.org/10.1111/jcpe.12427.

[13] Chatterjee, K., Hossain, S.A., Samarjit Kar (2018). Prioritization of project proposals in portfolio management using fuzzy AHP. OPSEARCH, Springer; Operational Research Society of India. 55(2), 478-501. DOI: 10.1007/s12597018-0331-3.

[14] King, S. S., Rahman, R. A., Fauzi, M. A., Haron, A.T. (2020). Mechanisms for addressing the impact of COVID- 19 on infrastructure projects. IOP Conference Series: Earth and Environmental Science. 682, 012047. 


\title{
Journal of Civil Engineering, Science and Technology
}

\author{
Volume 12, Issue 2, September 2021
}

[15] Wang, L. L., Lo, K., Chandrasekhar, Y., Reas, R., Yang, J., Eide, D., et. al. \& Kohlmeier, S. (2020). Cord-19: The covid-19 open research dataset. ArXiv. Available at: https://arxiv.org/abs/2004.10706.

[16] Ron Schipper, R.P.J., Gilbert Silvius, A.J.(2018). Towards a conceptual framework for sustainable project portfolio management. International Journal of Project Organisation and Management. 10(3), 191-221. 